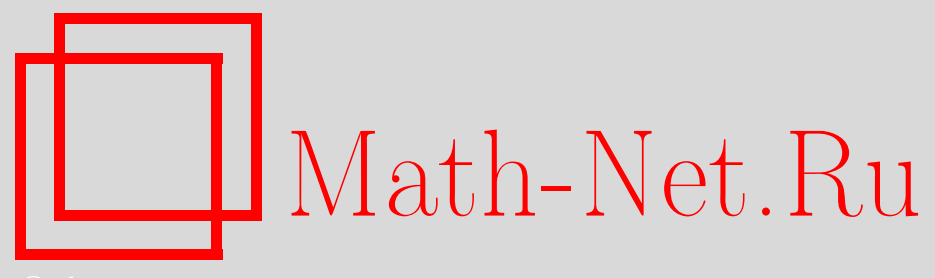

М. Шевцова, Многократная лемма Холла в задачах про мудрецов, Квант, 2019, номер 7, 27-31

DOI: https://doi.org/10.4213/kvant20190705

Использование Общероссийского математического портала Math-Net.Ru подразумевает, что вы прочитали и согласны с пользовательским соглашением http://www.mathnet.ru/rus/agreement

Параметры загрузки:

IP: 52.90 .164 .192

26 апреля 2023 г., 05:53:19

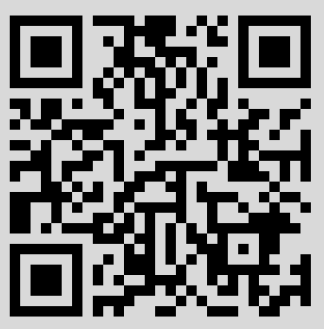




\section{Многократная лемма Холла \\ в задачах про мудрецов}

М.ШЕВЦОВА

\section{Введение}

Задачи, связанные с кооперативными алгоритмами (проще говоря, задачи о мудрецах) традиционно считаются довольно трудными. Дело в том, что зачастую придумать соответствующую стратегию действий, гарантирующую мудрецам успех (например, при отгадывании цветов колпаков, которые на них надеты), весьма непросто; нет какихто общих соображений, позволяющих строить нужные стратегии. Конечно, есть стандартные идеи нумерации, кодирования и т.д., но как именно занумеровать, закодировать и передать тем самым нужную информацию, приходится каждый раз придумывать заново.

В этой статье мы расскажем об интересном подходе к подобным задачам, при котором придумывать подобные стратегии действий не нужно. Это кажется невероятным, но есть способ доказать существование стратегии, не предъявляя ее явно! Те же идеи применимы к задачам о фокусниках: можно доказать возможность фокуса, не раскрывая способ его проведения! Как это можно сделать, мы узнаем, познакомившись с классическим комбинаторным результатом: леммой Холла.

\section{Обычная и многократная леммы Холла}

Начнем с формулировки классической леммы Холла. Представим себе, что вечером на танцы пришли юноши и девушки. Некоторые из юношей и девушек знакомы друг с другом. Как это часто бывает, каждый юноша хочет потанцевать только со знакомой

DOI: https://doi.org/10.4213/kvant20190705 ему девушкой. Спрашивается, смогут ли все юноши пригласить на танец знакомых им девушек? Оказывается, что существует простое необходимое и достаточное условие, при выполнении которого каждому юноше найдется пара (хотя, возможно, какие-то девушки при этом останутся без пары). В этом и заключается суть леммы Холла.

Теорема 1. Лемма Холла. Рассмотрим двудольный граф, где вершины первой доли - это юноши, а вершины второй доли девушки. Соединим ребром юношу и девушку, если они знают друг друга. Предположим, что любые $k$ юношей знают не меньше $k$ девушек, для любого $k$ от 1 до общего количества юношей. Тогда все юноши смогут пригласить на танеи знакомых им девушек.

Есть много разных способов доказать лемму Холла. Мы приведем классическое доказательство, которое еще называется методом чередующихся цепей. Другие доказательства можно найти в статье [1].

Доказательство. Предположим противное: пусть все юноши не смогут танцевать со знакомыми им девушками. Рассмотрим наибольшее количество танцующих пар, которое можно образовать. Далее рассмотрим юношу, не вошедшего в эти пары. Он начинает организовывать свое тайное общество. В первый день в этом обществе только он. Каждый следующий день каждый юноша, входящий в это общество, приглашает туда всех знакомых с ним девушек, а они приводят туда своих партнеров по танцу (если таковые есть).

\section{Упражнения}

1. Докажите, что рано или поздно в общество придет девушка, у которой не было пары.

2. Докажите, что в таком случае можно разбить юношей и девушек на пары так, чтобы количество пар увеличилось.

3. Выведите отсюда лемму Холла.

Суть леммы Холла заключается в установлении соответствий между двумя типами объектов (юноши и девушки) при выполнении некоторых условий связи между этими объектами. В комбинаторике существует не так уж много подобных утверждений, и лемма Холла - возможно, наиболее мощное из них. Чтобы потренироваться ее применять, попробуйте решить следующие задачи. 


\section{Упражнения}

4. Каждый из двух равновеликих квадратов разбит на 100 равновеликих частей. Докажите, что можно сложить эти квадраты в стопку и проткнуть в 100 точках так, чтобы каждая из 100 частей каждого из квадратов была проткнута.

5. Из шахматной доски вырезали 7 клеток. Докажите, что на оставшиеся клетки можно поставить 8 не бьющих друг друга ладей.

Указание. Рассмотрите двудольный граф, вершины которого - это строки (первая доля) и столбцы (вторая доля) данной таблицы.

На практике мы будем использовать лемму Холла в очень конкретной ситуации, соответствующей так называемому регулярному двудольному графу. Сформулируем отдельно соответствующее утверждение, которое и будет ключевым при решении задач с мудрецами.

Теорема 2. Лемма Холла для регулярного графа. Предположим, что для некоторого $l>0$ каждый юноша знает ровно $l$ девушек и каждая девушка знает ровно $l$ юношей. Тогда все юноши смогут пригла сить на танеи знакомых им девушек.

В терминах графов это утверждение звучит так: если в двудольном графе степени всех вершин одинаковы, то вершинам из одной доли можно сопоставить ровно по одной смежной вершине из другой доли.

Доказательство. Рассмотрим произвольных $k$ юношей и докажем, что они знают не менее $k$ девушек (в таком случае наше утверждение следует из леммы Холла). Предположим, что $k$ юношей знают $x$ девушек. Посчитаем количество ребер, исходящих из этих $k$ юношей, и количество ребер, входящих в знакомых им $x$ девушек. Ясно, что ребер, выходящих из юношей, не больше, чем ребер, входящих в девушек. Тогда $k l \leq x l$, откуда $x \geq k$, что и требовалось доказать.

Упражнение 6. В частном охранном предприятии работают $n$ охранников. Ежедневно им нужно распределяться по $n$ объектам. По прошествии $k$ дней оказалось, что никто дважды на одном объекте не дежурил. Докажите, что можно составить расписание на оставшиеся $n-k$ дней так, чтобы все охранники подежурили по одному разу на всех объектах.

В дальнейшем нам будут важны идеи, связанные с применением леммы Холла для решения задач про фокусников. Мы приве- дем лишь одну задачу на эту тему, отсылая заинтересованного читателя к статье [2].

Задача 1 (Всероссийская олимпиада по математике, 2007). Фокусник с помощником собираются показать такой фокус. Зритель пишет на доске последовательность из $N$ чифр. Помощник фокусника закрывает две соседних иифры черным кружком. Затем входит фокусник. Его задача - отгадать обе закрытые иифры ( и порядок, в котором они расположены). При каком наименьшем $N$ фокусник может договориться с помошником так, чтобы фокус гарантированно удался?

Ответ: 101.

Решение. Перед тем, как переходить к решению, попробуем понять, как можно формализовать отгадывание фокусником начальной расстановки цифр. У нас есть множество начальных наборов из $N$ цифр. Один из этих наборов пишет зритель - его и должен отгадать фокусник. Эти наборы составят первую долю в нашем двудольном графе. Сам фокусник при этом видит лишь часть этого набора с двумя закрытыми помощником цифрами. Эти наборы составят вершины второй доли двудольного графа.

Это простое соображение, позволяющее ввести в нашу задачу двудольный граф, подсказывает оценку для числа $N$. Рассмотрим все вершины второй доли. Этих вершин в точности $(N-1) \cdot 10^{N-2}$. С другой стороны, вершин в первой доле ровно $10^{N}$. Ясно, что если вершин во второй доле меньше, чем в первой, то фокус не удастся. Действительно, в таком случае найдутся два стартовых набора из $N$ цифр, которые после закрытия цифр дадут один и тот же набор, который увидит фокусник, поэтому угадать нужный набор он не сможет. Отсюда получаем ограничение на $N$ :

$$
(N-1) \cdot 10^{N-2} \geq 10^{N},
$$

откуда $N \geq 101$.

Осталось привести алгоритм действий фокусника, чтобы он мог угадать закрытые цифры в последовательности длины $N_{0}=101$. Вот здесь мы и применим лемму Холла.

Что нам нужно сделать? У нас есть вершины второй доли, которые видит фокусник, и вершины первой доли, которые загадал зритель. Нам нужно установить биекцию, т.е. 
взаимно-однозначное соответствие, между этими наборами. Более того, как мы установим биекцию, совершенно не важно! Важно лишь наличие такой биекции! Таким образом, можно доказать, что у фокусника получится отгадать цифры, не раскрывая секрет фокуса, т.е. не предъявляя явно способ отгадывания! В этом и заключается центральная идея этой статьи: доказывать существование биекций (или других, более сложных отображений), не строя их явно.

Покажем, как это можно сделать. Рассмотрим уже знакомый нам двудольный граф, в котором одна доля - это последовательности, которые может увидеть фокусник, а другая доля - это наборы, которые мог загадать зритель. Соединим две вершины в разных долях, если, закрыв в первой вершине какието две соседние цифры, можно получить вершину из второй доли. Заметим, что получившийся граф является регулярным. Действительно, при $N=101$ каждой последовательности из $N$ цифр соответствует $N-1=$ $=100$ способов закрыть в ней две соседние цифры. С другой стороны, для данной последовательности с двумя закрытыми цифрами имеется также $100=10 \cdot 10$ способов эти цифры восстановить. Значит, граф удовлетворяет условиям леммы Холла, и мы можем поставить в соответствие каждому набору цифр, загаданному зрителем, ровно один набор цифр, который увидит фокусник.

Таким образом, фокусник и помощник сначала должны выучить все соответствия между вершинами первой и второй долей (a всего этих соответствий ровно $10^{101}$ - столько, сколько вершин в любой из долей). Когда зритель напишет свою последовательность цифр, помощник вспоминает, какая вершина второй доли соответствует той, которая получилась у зрителя, и закрывает нужные цифры. Затем фокусник, входя в аудиторию, видит вершину второй доли и вспоминает, какой вершине первой доли она соответствует. Это позволяет ему назвать закрытые цифры.

Теперь сформулируем несколько более общее утверждение, которое мы будем называть многократной леммой Холла. Именно это утверждение будет для нас ключевым.

Опять рассмотрим юношей и девушек, пришедших на танцы, которые должны разбиться на пары так, чтобы в каждой паре партнеры знали друг друга. Но теперь усложним задачу. Предположим, что юноши должны станцевать ровно $m$ танцев каждый и по-прежнему танцевать они могут только со знакомыми им девушками. Однако девушки при этом не могут танцевать больше одного танца (в том числе и с тем же самым партнером). Оказывается, что гарантировать существование такого разбиения на группы «один юноша и $m$ девушек» можно с помощью условия, очень похожего на условие из обычной леммы Холла.

Теорема 3. Многократная лемма Холла. Рассмотрим двудольный граф, где вершины первой доли - это юноши, а вершины второй доли - девушки. Соединим ребром юношу и девушку, если они знают друг друга. Каждый юноша хочет танцевать с $m$ знакомыми девушками, причем каждая девушка не может танщевать два таниа (в том числе с одним юношей). Докажите, что если при любом $k$ для любого набора из $k$ юношей количество знакомых им в совокупности девушек не меньше $\mathrm{km}$, то каждьй юноша сможет станцевать т танцев.

Доказательство. Клонируем каждого юношу $m$ раз, и пусть каждый клон знает тех же девушек, что и изначальный юноша. Теперь рассмотрим двудольный граф, где вершины первой доли - это все клоны всех юношей, а вершины второй доли - это девушки. Покажем, что в полученном графе выполняется условие обычной леммы Холла, т.е. можно всех клонов юношей поставить в пары с различными знакомыми им девушками. Возьмем $s$ клонов. Заметим, что они знают тех же девушек, что и изначальные юноши, клонами которых они являются. А этих юношей было хотя бы $\frac{s}{m}$. По условию многократной леммы Холла, эти юноши знали хотя бы $\frac{s}{m} \cdot m=s$ девушек. Значит, эти $s$ клонов знают хотя бы $s$ девушек, т.е. условие леммы Холла выполняется.

Пусть теперь каждый юноша будет танцевать с теми девушками, которые были в парах с его клонами. Легко видеть, что данное разбиение является искомым.

Как и в случае с обычной леммой Холла, нам будет удобно использовать многократную лемму Холла в следующем частном случае. 
Теорема 4. Многократная лемма Холла в регулярном случае. Рассмотрим двудольный граф, где вершины первой доли - это юноши, а вершины второй доли - девушки. Соединим ребром юношу и девушку, если они знают друг друга. Предположим, что степени всех вершин, соответствующих юноиам, одинаковы и равны $m$ и степени всех вершин, соответствующих девушкам, также одинаковы и равны $d$. Докажите, что каждый юноша может станцевать с $\left[\frac{m}{d}\right]$ знакомыми ему девушками, причем каждая девушка при этом будет танщевать не более одного раза.

Упражнение 7. Докажите эту теорему.

\section{Мудрецы и многократная лемма Холла}

Итак, мы выяснили, как доказывать возможность проведения фокусов с помощью леммы Холла: ключевым является соображение о возможности установления инъекции между множеством стартовых состояний, которые видит фокусник, и множеством конечных (загаданных зрителем) состояний, которые нужно отгадать. Инъекция - это такое соответствие, что разным стартовым состояниям сопоставлены разные конечные. Однако в задачах с мудрецами и кооперативными стратегиями ситуация более сложная. Во-первых, в подавляющем большинстве таких задач мудрецы могут (и должны) ошибаться, т.е. безошибочного отгадывания просто не существует. Во-вторых, возможность наличия ошибок делает неоднозначным процесс декодирования. Иначе говоря, конечная ситуация, которую можно получить из стартовой, не однозначна. Но у нас на такой случай как раз есть многократная лемма Холла!

Ключевое соображение, позволяющее заставить многократную лемму Холла работать в задачах с мудрецами, заключается в следующем. Предположим, что мудрецам надели колпаки разных цветов и им нужно угадать цвет своего колпака, видя перед собой только колпаки других мудрецов. Занумеруем мудрецов и будем надевать на них колпаки всеми возможными способами. Вооружимся фотоаппаратом и начнем их фотографировать. Будем делать фотографию каждой ситуации сверху, чтобы были видны все шапки, а затем передадим фотоаппарат каждому из мудрецов, чтобы он сам сделал фотографии всех остальных мудрецов, которых он видит со своего места.

Рассмотрим двудольный граф, в котором вершины первой доли - это все фотографии, сделанные нами (по факту просто всевозможные начальные расположения колпаков на мудрецах), а вторая доля - это все фотографии, сделанные всеми мудрецами. Далее, соединим вершину $v$ из второй доли с вершиной $u$ из первой, если фотография $v$ сделана одним из мудрецов в ситуации $u$. Что должны сделать мудрецы? Для каждой сделанной им фотографии мудрец должен постараться восстановить цвет своего колпака. Разумеется, в некоторых случаях мудрецы ошибутся. Нам нужно найти тех мудрецов, которые гарантированно ответят верно. Точнее говоря, следует равномерно распределить ответы всех мудрецов по фотографиям $u$, чтобы на каждую фотографию приходилось достаточное количество правильных ответов.

Для этого воспользуемся многократной леммой Холла. Мудрецы, чьи точки зрения выбраны в соответствии с данной общей фотографией $u$, будут отвечать исходя из предположения, что они находятся в этой ситуации, а значит, правильно. Таким образом, если каждой фотографии $u$ поставлено в соответствие хотя бы $m$ фотографий $u_{1}, \ldots$ $\ldots, u_{m}$, сделанных мудрецами, то в каждой ситуации правильно ответят хотя бы $m$ мудрецов. Число $m$ мы определим из параметров задачи.

Посмотрим, как эта схема работает на практике.

Задача 2 (Московская математическая олимпиада, 2010). Команда из п мудрецов участвует в игре: на каждого из них надевают шапку одного из $k$ заранее известных иветов, а затем по свистку все мудрець одновременно выбирают себе по одному шарфу. Команда получает столько очков, у скольких ее участников цвет шапки совпал с иветом шарфа (шарфов и шапок любого ивета имеется достаточное количество; во время игры каждый участник не видит своей шапки, зато видит шапки всех остальных, но не имеет права выдавать до свистка никакую информацию). Какое наи большее число очков команда, заранее наме- 
тив план действий каждого ее члена, может гарантированно получить?

Ответ: $[n / k]$.

Решение. Рассмотрим описанный выше граф, в котором вершины первой доли - это всевозможные начальные позиции команды мудрецов (т.е. всевозможные варианты надеть на них шапки $k$ цветов), а вершины второй доли - это фотографии, сделанные каждым из мудрецов в каждой возможной стартовой ситуации. Ясно, что в первой доле $k^{n}$, а во второй $n k^{n-1}$ вершин.

Каждая вершина из первой доли соединена с $n$ вершинами из второй доли, так как такую рассадку может видеть каждый из $n$ мудрецов. С другой стороны, каждая вершина из второй доли соединена с $k$ вершинами из первой доли, так как у каждого мудреца есть $k$ вариантов цвета своего шарфа.

Теперь построим алгоритм действий для мудрецов, при котором они гарантированно наберут $[n / k]$ очков. Для этого достаточно доказать, что можно сопоставить каждой вершине из первой доли $[n / k]$ вершин из второй доли.

Воспользуемся многократной леммой Холла в регулярном случае. Применим эту лемму, сопоставив каждой начальной расстановке $u$ мудрецов из первой доли $m=[n / k]$ вершин из второй доли. Именно эти мудрецы ответят правильно при начальной расстановке $u$. Таким образом, мудрецы могут гарантированно набрать $[n / k]$ очков.

Осталось доказать, что больше $[n / k]$ очков гарантировать нельзя. На самом деле это также объясняется возможностью применения леммы Холла: если бы можно было сопоставить каждой вершине первой доли больше $[n / k]$ вершин из второй доли, то во второй доле нам просто не хватило бы вершин. Формально это можно доказать так. Предположим, что есть такая стратегия за мудрецов, которая гарантирует хотя бы $[n / k]+1$ очков. Заметим, что ответ каждого мудреца однозначно определяется цветом шапок у остальных мудрецов. Поставим в соответствие каждой фотографии из первой доли точки зрения мудрецов, которые в данной ситуации отвечают правильно. Если для каждой раскраски их больше $[n / k]$, то

$$
n k^{n-1} \geq k^{n}([n / k]+1)>k^{n}[n / k]=n k^{n-1}
$$

- противоречие. Таким образом, максималь- ное количество очков, набранных мудрецами, равно $[n / k]$.

Есть класс задач про мудрецов, где требуется найти наибольшую вероятность гарантированно угадать цвет своего колпака. Рассмотрим, например, следующие модификации предыдущей задачи.

\section{Упражнения}

8. В условиях предыдущей задачи будем считать, что $n<k$. С какой максимальной вероятностью хотя бы один из мудрецов угадает цвет своей шапки?

9. В этот раз мудрецы пишут предполагаемый цвет своего колпака $r$ раз, при этом они не видят, что написали их соседи. Какую максимальную вероятность того, что хотя бы один из них угадает за эти $r$ попыток, могут гарантировать мудрецы?

Задача 3 (Олимпиада имени Леонарда Эйлера, 2013). 99 мудрецов сели за круглый стол. Им известно, что пятидесяти из них надели колпаки одного из двух иветов, а сорока девяти остальным - другого (но заранее неизвестно, какого именно из двух цветов 50 колпаков, а какого-49). Каждый из мудрецов видит цвета всех колпаков, кроме своего собственного. Все мудрещы должны одновременно написать (каждый на своей бумажке) ивет своего колпака. Смогут ли мудрець заранее договориться отвечать так, чтобы не менее 74 из них дали верные ответы?

\section{Ответ: да.}

Решение. Понятно, что если мудрец видит 50 колпаков одного цвета, то у него колпак цвета, отличного от того, которого 50 , т.е. он знает свой колпак. Значит, 49 мудрецов знают цвет своего колпака и ответят правильно. Оставшихся 50 мудрецов, которые видят 49 колпаков одного цвета и 49 другого, будем называть невезучими.

Добьемся того, чтобы из невезучих мудрецов 25 каждый раз угадывали колпак правильно.

Рассмотрим описанный выше граф, в котором вершины первой доли - это всевозможные позиции команды мудрецов, а вершины второй доли - это фотографии, сделанные каждым из невезучих мудрецов в каждой возможной стартовой ситуации. Каждая вершина из первой доли соединена с 50 из

(Продолжение см. на с. 34) 
(Начало см. на с. 27)

второй, так как невезучих мудрецов в каждой ситуации 50. С другой стороны, каждая вершина из второй доли соединена с двумя вершинами из первой, так как у невезучего мудреца есть два варианта, какого цвета у него колпак. Теперь достаточно доказать, что можно сопоставить каждой вершине из первой доли 25 вершин из второй доли.

Для этого опять воспользуемся многократной леммой Холла. К каждой начальной расстановке (назовем ее $u$ ) мудрецов из первой доли будут сопоставлены 25 вершин из второй доли. Именно эти мудрецы ответят правильно при начальной расстановке $u$. Таким образом мудрецы гарантированно смогут угадать $25+49=74$ раза.

Задача 4 (Математический праздник, 2011). Дракон запер в пешере шестерых гномов и сказал: «У меня есть семь колпаков семи цветов радуги. Завтра утром я завяжу вам глаза и надену на каждого по колпаку, а один колпак спрячу. Затем сниму повязки, и вы сможете увидеть колпаки на головах у других, но общаться я вам уже не позволю. После этого каждый втайне от других скажет мне цвет спрятанного колпака. Если угадают хотя бы трое, всех отпущу. Если меньше - съем на обед». Смогут ли гномы заранее договориться действовать так, чтобы спастись?

Решение. Рассмотрим описанный выше граф, где вершины первой доли - это всевозможные позиции команды гномов, а вершины второй доли - это фотографии, сделанные каждым из гномов в каждой возможной стартовой ситуации. Каждая вершина из первой доли соединена с 6 вершинами из второй, так как гномов всего 6. Далее, каждая вершина из второй доли соединена с 2 вершинами из первой, так как всего цветов 7 , а один гном видит 5 из них, значит, его колпак одного из двух оставшихся цветов. Теперь составим алгоритм действий гномов, при котором они гарантированно смогут угадать 3 раза. Для этого достаточно доказать, что можно сопоставить каждой вершине из первой доли 3 из второй. Воспользуемся многократной леммой Холла: каждой начальной расстановке гномов $u$ из первой доли сопоставим 3 вершины из второй доли. Именно эти гномы ответят правильно при начальной расстановке $u$. Таким образом гномы могут гарантированно угадать 3 раза и спастись.

Рассмотрим обобщение двух предыдущих задач.

Задача 5. Есть колпаки киветов, каждого по $m$ штук. Один колпак убирают, а остальные тк - 1 надевают на мудречов. После этого мудрецы называют цвет свое$2 о$ колпака. Какое максимальное количество правильных ответов могут гаранти ровать мудрещь?

$$
\text { Ответ: }\left[\frac{m(k-1)}{2}\right]+m-1 \text {. }
$$

Решение. Понятно, что если мудрец видит ровно $m-2$ колпака одного из цветов, то у него колпак этого цвета и он ответит правильно. Значит, $m-1$ правильный ответ мудрецы дать смогут.

Если же мудрец такого цвета не видит, то на нем колпак одного из цветов, которых по $m$ штук. Такой мудрец видит $k-2$ группы колпаков одного цвета по $m$ колпаков и 2 группы по $m-1$ колпаку. Тем самым, у этого мудреца 2 варианта, в каком он колпаке. Рассмотрим двудольный граф, где одна доля - фотографии, сделанные такими сомневающимися мудрецами, а другая - раскраски. Соединим каждую раскраску с сомневающимися в ней мудрецами. Тогда степень каждой раскраски равна $m(k-1)$. По многократной лемме Холла мы можем сопоставить каждой раскраске по $\left[\frac{m(k-1)}{2}\right]$ мудрецов. Таким образом, угадают в каждой раскраске по $\left[\frac{m(k-1)}{2}\right]+m-1$ раз.

Упражнение 10. Докажите, что больше $\left[\frac{m(k-1)}{2}\right]+m-1$ мудрецов не смогут отгадать цвет своего колпака.

Автор благодарит П.В. Бибикова за помощь в подготовке статьи и внимание к работе.

\section{Литература}

1. А.Романов. Задачи и теоремы о представителях. - «Квант», 2015, №1.

2. А. Эвнин. Задачи о фокусниках и теоремы Холла и Шпернера. - «Квант», 2019, №2. 